\title{
Procalcitonin as a biomarker for infection and sepsis: Yet again
}

\author{
John L Moran ${ }^{1 *}$ and Patricia J Solomon ${ }^{2}$ \\ ${ }^{1}$ Department of Intensive Care Medicine, The Queen Elizabeth Hospital, Woodville SA 5011, Australia \\ ${ }^{2}$ School of Mathematical Sciences, University of Adelaide, Adelaide SA 5000, Australia
}

Biomarkers may be characterized as diagnostic, distinguishing between two states (say, infected or non-infected); prognostic, informing of a likely outcome (say, mortality); or predictive, if a treatment effect is differential between biomarker positivity and negativity [1]. One of the most discussed biomarkers in the infectious diseases and critical care literature is procalcitonin [2-4], a polypeptide that serves as the precursor for calcitonin in thyroid gland $\mathrm{C}$ cells and is released in response to microbial toxins and pro-inflammatory mediators [5]. Procalcitonin qualifies as both a diagnostic (an infection or sepsis marker) and predictive (a guide to antimicrobial therapy) biomarker. This being said, procalcitonin biomarker performance has been subjected to a large number of meta-analyses [6-20], suggesting a degree of disquiet regarding the actual level of evidence for procalcitonin utility.

We first summarize certain key parameters of procalcitonin performance as a diagnostic biomarker in 6 meta-analyses, conducted between the years of 2004-2015; author sub-group analyses are not considered (Table 1) [11,14,16-19]. Where reported, heterogeneity was a marked feature, even when restricted to a more circumscribed population of the "critically ill"; the components of heterogeneity presumably reflecting such factors as different procalcitonin assays and threshold levels, patient subgroups, endpoint prevalence, primary study inclusions and exclusions, and study quality / bias [5]. Analytic methods reflected year of publication, with the earlier studies [16-19] using the linear regression model of Moses et al, as opposed to the mixed-effects bivariate approach of the two more recent studies [11,14]; a point of importance for Wacker and co-authors [14]. Overall, the diagnostic performance could at best be described as modest, a point conceded by some of the authors $[11,16,18]$ and reiterated by Afshari and Harbath [22], commenting upon the somewhat fulsome conclusions of Wacker et al. [14]. The former noted that the sensitivity of $77 \%$ corresponded to $23 \%$ of patients not receiving adequate therapy and a specificity of $79 \%$ corresponded to $21 \%$ being unnecessarily treated (Table 1); similarly, a positive likelihood ratio of 3.67 and a negative likelihood ratio of 0.29 , being small and containing no information, were "... of little use for guiding initial treatment decisions", especially in the critically ill with a high pre-test sepsis probability [22]. As diagnostic meta-analyses have had a history of poor reporting [23] compared with meta-analyses reporting treatment effects of randomized controlled trials, the attendant vigorous correspondence [22, 24-29] to some of the above meta-analyses is perhaps not surprising.

One outstanding feature of these diagnostic meta-analyses was the variable cut-point procalcitonin thresholds used in the primary studies. Again in a response to the meta-analysis of Wacker et al. [14], Ruecker and Schumacher [28] suggested, in agreement with a preliminary observation by Wacker et al, that "investigators of the primary studies seemed to select cutoffs such that they maximised the sum of sensitivity and specificity". They further elaborated an analysis that modelled the assumption that the investigators of the primary studies selected their cutoff such that it maximised a weighted sum of sensitivity (Se) and specificity (Sp): $\lambda \cdot \mathrm{Se}+(1-\lambda) . \mathrm{Sp} ; \lambda$ (between 0 and 1 ) was the weight the study investigators attributed to the sensitivity and a $\lambda$ of 0.5 attributed equal weights to sensitivity and specificity, equivalent to maximisation of the Youden index. The estimate of $\lambda$ was 0.491 , quite close to 0.5 , supporting their initial hypothesis. Estimates of pooled sensitivity and specificity were 0.72 and 0.73 , even less that those estimates subjected to critique by Afshari and Harbath [22]. In a more recent study Steinhauser et al [30] proposed to model the distribution functions of the underlying biomarker by applying a linear mixed effects model, accounting for a cross-study heterogeneity and dependence (or correlation) of sensitivity and specificity. That is, an attempt was made to utilize all of the available information. Again accessing data from the meta-analysis of Wacker et al. [14], 54 data points in total for 26 different values of the procalcitonin thresholds were obtained, yielding a model sensitivity of $0.71(0.63 ; 0.78)$ and a specificity of $0.81(0.74$; $0.86]$, similar to the previous estimates of Ruecker and Schumacher [28]. The estimated optimal threshold for procalcitonin in this analysis was $1.2 \mathrm{ng} / \mathrm{ml}$. Such an approach to the problem of multiple diagnostic thresholds appears to be a most promising initiative and has been implemented in at least one independent study [31].

Given that procalcitonin as a diagnostic biomarker for sepsis / infection has consistently failed to achieve sensitivities and specificities above $80 \%$ (Table 1), it may be surprising that its use has been incorporated into a number of randomized controlled trials as an antibiotic stewardship guide. How are we to understand this? As with any biological variable, single measurements will be subject to random variability and measurement error, potentially generating regression dilution bias and regression to the mean, and repeated measurement would be, prima facie, preferable [32]. Thus algorithms incorporating time-dependent (daily or otherwise) procalcitonin assays have been incorporated into decision-making with respect to anti-biotic prescription [33].

The accumulation of RCTs over time obviously limits a definitive answer to the utility of procalcitonin as a predictive biomarker. We

Correspondence to: John L Moran, Department of Intensive Care Medicine, The Queen Elizabeth Hospital, 28 Woodville Road, Woodville SA 5011 Australia, Tel. 6108 8222 6463; Fax, 6108 8222 6045; E-mail. john.moran@adelaide.edu.au

Received: June 16, 2017; Accepted: June 28, 2017; Published: June 30, 2017 
Table 1. Meta-analysis of Prolactin measurement in the years of 2004-20015

\begin{tabular}{|c|c|c|c|c|c|c|}
\hline Study & Simon & Uzzan & Tang & Jones & Wacker & Hoeber \\
\hline Year & 2004 & 2006 & 2007 & 2007 & 2013 & 2015 \\
\hline Endpoint & Infection & Sepsis & Sepsis & Bacteraemia & Sepsis & Bacteraemia \\
\hline Population & hospitalised & ICU \& trauma & critically ill & ambulatory & critically ill & hospitalized \\
\hline Analytic method & regression model & regression model & regression model & regression model & bivariate model & bivariate model \\
\hline Prevalence (\%) & & & 31,88 & 4,54 & 34,88 & \\
\hline \multicolumn{7}{|l|}{ Parameters } \\
\hline Total n & & 3943 & 2097 & 2008 & 3244 & 16514 \\
\hline Pct cut-off (ng/mL) & & $0.6,5$ & 2,20 & $0.5-2$ & $1.1(0.5,2.0)$ & 0.5 \\
\hline$I^{2}(\%: 95 \% C I)$ & & & 52.6 & 64 & $96(94,99)$ & 86 \\
\hline (S)ROC (95\%CI) & & & $0.79(0.73,0.83)$ & $0.84(0.75,0.90)$ & $0.85(0.81,0.88)$ & 0.79 \\
\hline Sens (\%: 95\%CI) & $88(80,93)$ & 42,97 & $71(67,76)$ & $76(66,84)$ & $77(72,81)$ & $76(72,80)$ \\
\hline Spec (\%: 95\%CI) & $81(67,90)$ & 48,100 & $71(67,76)$ & $70(60,79)$ & $79(74,84)$ & $69(64,72)$ \\
\hline$+\mathbf{L R}$ & $3.58(2.99,4.28)$ & & $3.03(2.51,3.65)$ & & 3.67 & \\
\hline$-L R$ & $0.18(0.15,0.23)$ & & $0.43(0.37,0.48)$ & & 0.29 & \\
\hline ORd $(95 \% \mathrm{CI})$ & & $15.7(9.1,27.1)$ & $7.79(5.86,10.35)$ & $9.96(5.72,17.02)$ & & \\
\hline
\end{tabular}

Pct: procalcitonin; (S)ROC: (Summary) Receiver Operator Characteristic Curve; Sens: sensitivity; Spec: specitivity; +LR: positive likelihood ratio; -LR: negative likelihood ratio; Ord: diagnostic odds ratio; $\mathrm{CI}$ : confidence interval

present snapshots at the publication juncture of two reviews; by Pavoa and Sullah in 2012 and Andrioli and co-workers in 2017 [6,34]. The former reviewers cited 7 randomized controlled trials (2007 to 2011) assessing the role of procalcitonin-guided antibiotic stewardship in adult critically ill patients. Despite repeated association of this stewardship with a decrease in the duration of antibiotic therapy, the authors identified several trial limitations; high rate of patient exclusion and algorithm overruling, long duration of antibiotic therapy in the control group, disregarding of the effect of renal failure on procalcitonin level, and possible higher mortality and higher late organ failure in the procalcitonin arm. They concluded that the role of procalcitonin-guided antibiotic stewardship was "uncertain" [34]. Andrioli et al identified 10 trials with 1215 participants (search date to July 2015) and were more forthright in their conclusions: "Up-todate evidence of very low to moderate quality, with insufficient sample power per outcome, does not clearly support the use of procalcitoninguided antimicrobial therapy to minimize mortality, mechanical ventilation, clinical severity, reinfection or duration of antimicrobial therapy of patients with septic conditions" [6]. However the authors reported a second search in October 2016 and identified 3 further trials (not included in their analysis) with a total of 2695 participants; two multi-site and one single-centre [35-37]. It is not the purpose of this paper to conduct yet another meta-analysis of the use of procalcitonin; a simple search conducted using Web of Science ${ }^{\mathrm{ms}}$ on June $26^{\text {th }}$ with the terms "procalcitonin" and "meta-analysis" identified 191 hits. We suffice to summarize the results of the two multi-site trials. Bloos et al. recruited 1089 patients with severe sepsis or septic shock and found no mortality effect of procalcitonin-guided antimicrobial therapy, but a reduction of antibiotic exposure by $4.5 \%$, with no influence on resource utilization. They concluded that "The application of a procalcitoninguided algorithm needs further evaluation" [35]. De Jong et al [36] enrolled 1546 critically ill patients with assumed or proven infection and found an unexpected $5.4 \%(\mathrm{p}=0.01) 28$-day mortality reduction and a decrease in both antibiotic consumption and treatment duration with procalcitonin-guided antimicrobial therapy. Of interest, the mean per patient saving in antibiotic costs of $€ 34$ (with an average of 7 procalcitonin measurements per patient) had a break-even cost for procalcitonin of less than $€ 4$ per measurement. At the hospital of the authors of this paper the cost per measurement is $€ 38$. Again, adherence to the antibiotic stopping rules was variable (40-50\%) in both studies.

Where do we stand? A single procalcitonin measurement in, say, the emergency department or intensive care unit of a hospital would not appear to be of benefit in guiding decision making for diagnosis and therapy of infection/sepsis. The benefits or otherwise of procalcitoninguided antimicrobial therapy are still uncertain and would appear to depend upon the cost and medical structure of each jurisdiction.

\section{References}

1. Ballman KV (2015) Biomarker: Predictive or Prognostic? Journal of Clinical Oncology 33: 3968-3971.

2. Carrol ED, Thomson AP, Hart CA (2002) Procalcitonin as a marker of sepsis. Int $J$ Antimicrob Agents 20: 1-9. [Crossref]

3. Becker KL, Snider R, Nylen ES (2008) Procalcitonin assay in systemic inflammation, infection, and sepsis: Clinical utility and limitations. Crit Care Med 36: 941-952. [Crossref]

4. Reinhart K, Bauer M, Riedemann NC, Hartog CS (2012) New approaches to sepsis molecular diagnostics and biomarkers. Clin Microbiol Rev 25: 609-634. [Crossref]

5. Schuetz P, Bretscher C, Bernasconi L, Mueller B (2017) Overview of procalcitonin assays and procalcitonin-guided protocols for the management of patients with infections and sepsis. Expert Rev Mol Diagn 17: 593-601. [Crossref]

6. Andriolo BN, Andriolo RB, Salomao R, Atallah AN (2017) Effectiveness and safety of procalcitonin evaluation for reducing mortality in adults with sepsis, severe sepsis or septic shock. Cochrane Database Syst Rev. [Crossref]

7. Liu Y, Hou J, Li Q, Chen K, Wang S, et al. (2016) Biomarkers for diagnosis of sepsis in patients with systemic inflammatory response syndrome: a systematic review and meta-analysis. Springerplus 5: 2091. [Crossref]

8. Li Chen, Cong Feng, Jing Dong, Yongzhi Zhai, Xin Chen, et al. (2016) Procalcitonin levels correlates with the pathogeny and severity of community acquired pneumonia: a meta-analysis. International Journal of Clinical and Experimental Medicine 9: 1376313772 .

9. Wu CW, Wu JY, Chen CK, Huang SL, Hsu SC, et al. (2015) Does procalcitonin, C-reactive protein, or interleukin-6 test have a role in the diagnosis of severe infection in patients with febrile neutropenia? A systematic review and meta-analysis. Support Care in Cancer 23: 2863-2872. [Crossref]

10. Vikse J, Henry BM, Roy J, Ramakrishnan PK, Tomaszewski KA, et al. (2015) The role of serum procalcitonin in the diagnosis of bacterial meningitis in adults: a systematic review and meta-analysis. Int J Infect Dis 38: 68-76. [Crossref]

11. Hoeboer SH, van der Geest PJ, Nieboer D, Groeneveld AB (2015) The diagnostic accuracy of procalcitonin for bacteraemia: a systematic review and meta-analysis. Clin Microbiol Infect 21: 474-481. [Crossref]

12. Chengfen Y, Tong L, Xinjing G, Zhibo L, Lei X (2015) [Accuracy of procalcitonin for diagnosis of sepsis in adults: a Meta-analysis]. Zhonghua Wei Zhong Bing Ji Jiu Yi Xue 27: 743-749. [Crossref]

13. Yu CW, Juan LI, Wu MH, Shen CJ, Wu JY, et al. (2013) Systematic review and metaanalysis of the diagnostic accuracy of procalcitonin, C-reactive protein and white blood cell count for suspected acute appendicitis. Br J Surg 100: 322-329. [Crossref] 
14. Wacker C, Prkno A, Brunkhorst FM, Schlattmann P (2013) Procalcitonin as a diagnostic marker for sepsis: a systematic review and meta-analysis. Lancet Infect Dis 13: 426-435. [Crossref]

15. Tang H, Huang T, Jing J, Shen H, Cui W (2009) Effect of Procalcitonin-Guided Treatment in Patients with Infections: a Systematic Review and Meta-Analysis. Infection 37: 497-507. [Crossref]

16. Tang BM, Eslick GD, Craig JC, McLean AS, et al., (2007) Accuracy of procalcitonin for sepsis diagnosis in critically ill patients: systematic review and meta-analysis. Lancet Infect Dis 7: 210-217. [Crossref]

17. Uzzan B, Cohen R, Nicolas P, Cucherat M, Perret GY (2006) Procalcitonin as a diagnostic test for sepsis in critically ill adults and after surgery or trauma: a systematic review and meta-analysis. Crit Care Med 34: 1996-2003. [Crossref]

18. Simon L, Gauvin F, Amre DK, Saint-Louis P, Lacroix J (2004) Serum Procalcitonin and C-Reactive Protein Levels as Markers of Bacterial Infection: A Systematic Review and Meta-analysis. Clinical Infectious Diseases 39: 206-2017. [Crossref]

19. Jones AE, Fiechtl JF, Brown MD, Ballew JJ, Kline JA (2007) Procalcitonin test in the diagnosis of bacteremia: a meta-analysis. Ann Emerg Med 50: 34-41. [Crossref]

20. Heyland DK, Johnson AP, Reynolds SC, Muscedere J (2011) Procalcitonin for reduced antibiotic exposure in the critical care setting: A systematic review and an economic evaluation. Crit Care Med 39: 1792-1799. [Crossref]

21. Moses LE, Shapiro D, Littenberg B (1993) Combining Independent Studies of a Diagnostic-Test Into A Summary Roc Curve - Data-Analytic Approaches and Some Additional Considerations. Stat Med 12: 1293-1316. [Crossref]

22. Afshari A, Harbarth S (2013) Procalcitonin as diagnostic biomarker of sepsis. Lancet Infect Dis 13: 382-384. [Crossref]

23. Korevaar DA, van Enst WA, Spijker R, Bossuyt PM, Hooft L (2014) Reporting quality of diagnostic accuracy studies: a systematic review and meta-analysis of investigations on adherence to STARD. Evid Based Med 19: 47-54. [Crossref]

24. Simon L, Gauvin F, Amre D-á, SaintGÇÉLouis P, Lacroix J: Reply to Knudsen and Kristiansen. Clinical Infectious Diseases 2005, 40(9):1373-1374. [Crossref]

25. Tang BM, Eslick GD (2007) Procalcitonin for sepsis: Methodological issues in metaanalysis lead to further uncertainty. Crit Care Med 35: 679-679. [Crossref]
26. Tang BMP, Eslick GD, Craig JC, Mclean AS: Meta-analysis of procalcitonin for sepsis detection - Authors' reply. Lancet Infectious Diseases 2007, 7(8):502-503. [Crossref]

27. Uzzan B, Cohen R, Nicolas P, Cucherat M, Perret GY: Procalcitonin for sepsis Methodological issues in meta-analysis lead to further uncertainty - Reply. Critical Care Medicine 2007, 35(2):679-680. [Crossref]

28. Ruecker, G. and M. Schumacher, (2013) Procalcitonin as a diagnostic marker for sepsis. Lancet Infect Dis 13: 1012-1013.

29. Schlattmann P, Brunkhorst FM: Procalcitonin as a diagnostic marker for sepsis. Lancet Infect Dis 2014, 14(3):189-189. [Crossref]

30. Steinhauser S, Schumacher M, Rücker G (2016) Modelling multiple thresholds in metaanalysis of diagnostic test accuracy studies. BMC Med Res Methodol 16: 97. [Crossref]

31. Minnerup J, Broocks G, Kalkoffen J, Langner S, Knauth M, et al. (2016) Computed Tomography-Based Quantification of Lesion Water Uptake Identifies Patients within 4.5 Hours of Stroke Onset: A Multicenter Observational Study. Ann Neurol 80: 924934. [Crossref]

32. Hutcheon JA, Chiolero A, Hanley JA (2010) Random measurement error and regression dilution bias. BMJ 340: c2289. [Crossref]

33. van Oers JAH, Nijsten MW, Girbes AR (2017) Procalcitonin-Guided Antimicrobial Therapy-All About the Algorithm. JAMA Intern Med 177: 142-142.

34. Póvoa P1, Salluh JI (2012) Biomarker-guided antibiotic therapy in adult critically ill patients: a critical review. Ann Intensive Care 2: 32. [Crossref]

35. Bloos F1, Trips E2, Nierhaus A3, Briegel J4, Heyland DK, et al. (2016) Effect of Sodium Selenite Administration and Procalcitonin-Guided Therapy on Mortality in Patients with Severe Sepsis or Septic Shock A Randomized Clinical Trial. JAMA Int Med 176: 1266-1276. [Crossref]

36. de Jong E, van Oers JA, Beishuizen A, Vos P, Vermeijden WJ, et al. (2016) Efficacy and safety of procalcitonin guidance in reducing the duration of antibiotic treatment in critically ill patients: a randomised, controlled, open-label trial. Lancet Infect Dis 16: 819-827. [Crossref]

37. Najafi A, Khodadadian A, Sanatkar M, Shariat Moharari R, Etezadi F, et al. (2015) The Comparison of Procalcitonin Guidance Administer Antibiotics with Empiric Antibiotic Therapy in Critically Ill Patients Admitted in Intensive Care Unit. Acta Med Iran 53 562-567. [Crossref]

Copyright: (C2017 Moran JL. This is an open-access article distributed under the terms of the Creative Commons Attribution License, which permits unrestricted use, distribution, and reproduction in any medium, provided the original author and source are credited. 